\title{
DHA protects PC12 cells against oxidative stress and apoptotic signals through the activation of the NFE2L2/HO-1 axis
}

\author{
MARIA ELISABETTA CLEMENTI ${ }^{1 *}$, GIACOMO LAZZARINO $^{2,3^{*}}$, \\ BEATRICE SAMPAOLESE ${ }^{1}$, ANNA BRANCATO ${ }^{4}$ and GIUSEPPE TRINGALI ${ }^{3,5}$
}

\begin{abstract}
${ }^{1}$ CNR-ICRM Institute of 'Chemistry of Molecular Recognition', c/o Institute of Biochemistry and Clinical Biochemistry, Catholic University Medical School; ${ }^{2}$ Institute of Biochemistry and Clinical Biochemistry, Catholic University Medical School; ${ }^{3}$ A. Gemelli University Polyclinic Foundation, Italy IRCCS, I-00168 Rome; ${ }^{4}$ Department of Science for Health Promotion and Mother-Child Care 'G. D'Alessandro' University of Palermo, I-90127 Palermo;

${ }^{5}$ Institute of Pharmacology, Catholic University Medical School, I-00168 Rome, Italy
\end{abstract}

Received October 11, 2018; Accepted April 10, 2019

DOI: $10.3892 /$ ijmm.2019.4170

\begin{abstract}
Docosahexaenoic acid (DHA) is an omega-3 polyunsaturated fatty acid, derived mainly from fish oil. It is well known that DHA is present in high concentrations in nervous tissue and plays an important role in brain development and neuroprotection. However, the molecular mechanisms underlying its role remain to be fully elucidated. In this study, to enhance our understanding of the pathophysiological role of DHA, we investigated the possible neuroprotective mechanisms of action of DHA against hydrogen peroxide $\left(\mathrm{H}_{2} \mathrm{O}_{2}\right)$-induced oxidative damage in a rat pheochromocytoma cell line (PC12). Specifically, we evaluated the viability, oxidation potential, and the expression and production of antioxidant/cytoprotective enzymes, and eventual apoptosis. We found that pre-treatment with DHA $(24 \mathrm{~h})$ protected the cells from $\mathrm{H}_{2} \mathrm{O}_{2}$-induced oxidative damage. In particular, pre-treatment with DHA: i) Antagonized the consistent decrease in viability observed following exposure to $\mathrm{H}_{2} \mathrm{O}_{2}$ for $24 \mathrm{~h}$; ii) reduced the high levels of intracellular reactive oxygen species (ROS) associated with $\mathrm{H}_{2} \mathrm{O}_{2}$-induced
\end{abstract}

Correspondence to: Dr Maria Elisabetta Clementi, CNR-ICRM Institute of 'Chemistry of Molecular Recognition', c/o Institute of Biochemistry and Clinical Biochemistry, Catholic University Medical School, Largo F. Vito 1, I-00168 Rome, Italy

E-mail: e.clementi@icrm.cnr.it

*Co-first authorship

Abbreviations: DHA, docosahexaenoic acid; NFE2L2, nuclear factor (erythroid-derived 2)-like 2; HO-1, heme-oxygenase-1; ARE, antioxidant response element; GSH, reduced glutathione; Keap1, Kelch-like ECH-associated protein 1; NQO1, NAD(P)H:quinone oxidoreductase 1; CAT, catalase; GSH-Px, glutathione peroxidase; SOD, superoxide dismutase

Key words: docosahexaenoic acid, oxidative stress, apoptosis, nuclear factor (erythroid-derived 2)-like 2, heme oxygenase-1 oxidative stress; iii) increased the intracellular levels of enzymatic antioxidants [superoxide dismutase (SOD) and glutathione peroxidase (GSH-Px)] both under basal conditions and following $\mathrm{H}_{2} \mathrm{O}_{2}$ exposure; iv) augmented the intracellular levels of reduced glutathione (GSH) and ascorbic acid, while it reduced the malondialdehyde (MDA) levels under conditions of oxidative stress; v) upregulated the expression of nuclear factor (erythroid-derived 2)-like 2 (NFE2L2) and its downstream target protein, heme-oxygenase-1 (HO-1); and vi) induced an anti-apoptotic effect by decreasing Bax and increasing $\mathrm{Bcl} 2$ expression. These findings provide evidence suggesting that DHA is able to prevent $\mathrm{H}_{2} \mathrm{O}_{2}$-induced oxidative damage to $\mathrm{PC} 12$ cells, which is attributed to its antioxidant and anti-apoptotic effects via the regulation NFE2L2/HO-1 signaling. Therefore, DHA may play protective role in neurodegenerative diseases associated with oxidative stress.

\section{Introduction}

A number of studies have indicated that the brains of patients with neurodegenerative disease (such as brain stroke, Parkinson's and Alzheimer's diseases) is subjected to increased oxidative stress, induced by an imbalanced redox states $(1,2)$. The excessive generation of reactive oxygen species (ROS) and the dysfunction of the antioxidant system are widely condisered to be responsible for neuronal degeneration (3). Neurodegenerative processes are mostly mediated by ROS, as well as hydrogen peroxide $\left(\mathrm{H}_{2} \mathrm{O}_{2}\right)$, superoxide anion and hydroxyl radicals, which are generated as products of normal or altered metabolic processes that utilize molecular oxygen. ROS, produced by oxidative stress-caused mitochondrial damage, can damage the proteins, nucleic acids and polyunsaturated fatty acids of cell membranes. The consequent alterations of cellular functions and membrane integrity lead to cellular apoptosis or necrosis (4).

Antioxidant therapy has been suggested for the prevention and treatment of neurodegenerative diseases; in particular, an increased dietary intake of polyunsaturated fatty acids (PUFAs) is considered an efficient strategy for the prevention of neurological disorders (5). In this regard, the use of 
docosahexaenoic acid (DHA), the main $\omega$-3-PUFA in the mammalian brain, plays a crucial role in the development, function and protection of brain neurons (6). In fact, several studies have highlighted that the consumption of DHA, but not that of other $\mathrm{n}-3$ fatty acids, is associated with a reduced risk of stroke and cognitive decline or dementia $(7,8)$. Although the molecular mechanisms regarding its efficacy in the prevention of neurodegenerative disease are not yet entirely clear, it is considered that DHA protects the cells from oxidative stress by the synthesis of factors responsible for cellular defense mechanisms (9). Among these elements, nuclear factor (erythroid-derived 2)-like 2 (NFE2L2) represents one of the most important protective agents against oxidative stress (10-12). The activation of NFE2L2 induces the transcriptional regulation of various antioxidant enzymes, such as heme-oxygenase-1 (HO-1) and $\mathrm{NAD}(\mathrm{P}) \mathrm{H}$ :quinone oxidoreductase 1 (NQO1), as well as the modulation of apoptosis-related genes (13).

Within this framework, the present study was designed with an aim to obtain a better understanding of the mechanisms underlying the cellular protective effects of DHA. Therefore, using an in vitro $\mathrm{H}_{2} \mathrm{O}_{2}$-induced $\mathrm{PC} 12$ cell oxidative damage model, we examined the associations among the antioxidant effects of DHA pre-treatment and ROS production, mitochondrial membrane potential $(\Delta \Psi \mathrm{m})$, apoptosis and the activation of the NFE2L2/antioxidant response element (ARE) signaling pathway, in order to provide a possible explanation for the protective effects of DHA.

\section{Materials and methods}

Cell line, culture and treatments. PC12 cells (a cellular line of rat pheochromocytoma from Sigma-Aldrich Co., St. Louis, MO, USA. Cat. no. 88022401) were cultured in a $5 \% \mathrm{CO}_{2}$ atmosphere at $37^{\circ} \mathrm{C}$ in RPMI with $10 \mathrm{mM}$ HEPES, $1.0 \mathrm{~g} / \mathrm{l}$ glucose, $3.7 \mathrm{~g} / 1 \mathrm{NaHCO}_{3}, 100 \mathrm{U} / \mathrm{ml}$ penicillin, $100 \mu \mathrm{g} / \mathrm{ml}$ streptomycin, $10 \%$ fetal calf serum and $15 \%$ horse serum. Once grown to $85 \%$ confluence, the cells were subcultured at an appropriate density according to each experimental procedure.

The cells were treated with a physiological concentration $(60 \mu \mathrm{M})$ of DHA (purchased from Sigma-Aldrich Co.) $24 \mathrm{~h}$ prior to and during $\mathrm{H}_{2} \mathrm{O}_{2}$ exposure (for a further $24 \mathrm{~h}$ ). For the control groups, medium or $\mathrm{H}_{2} \mathrm{O}_{2}$ alone were used where appropriate. DHA was dissolved in $99.5 \%$ ethanol to prepare a $500 \mathrm{mM}$ stock solution; prior to use, DHA was complexed (1:2) to bovine serum albumin (BSA) and diluted in RPMI to the required concentration. The concentration of $\mathrm{H}_{2} \mathrm{O}_{2}$ used was $300 \mu \mathrm{M}$; since, in a previous series of dose-response experiments, described in detail in (14), we demonstrated that after $24 \mathrm{~h}, \mathrm{H}_{2} \mathrm{O}_{2}$ resulted in a reduction of the viability of $\mathrm{PC} 12$ cells of $50 \%$ at this concentration. At the end of all the experiments, the cells were collected and stored at $37^{\circ} \mathrm{C}$ (unless otherwise stated) for the analytical experiments.

Measurement of cell viability and intracellular ROS production. For the determination of cell viability and ROS production, the PC12 cells were plated in 96-well plates at a density of 10,000 cells/well and incubated with DHA $24 \mathrm{~h}$ prior to exposure to $\mathrm{H}_{2} \mathrm{O}_{2}$. Cell survival was evaluated by the 3-[(4,5-dimethylthiazol-2-yl)5,3-carboxymethoxyphenyl]-2-(4-sulfophenyl)-2H tetrazolium, inner salt reduction assay (MTS). The MTS assay (Promega srl, Padova, Italy) is a sensitive measurement of the normal metabolic status of cells, which reflects early cellular redox changes. The intracellular soluble formazan produced by the cellular reduction of the MTS was determined by recording the absorbance of each 96-well plate using the automatic microplate photometer (BioTek $^{\mathrm{TM}}$ Elx800 -Box 998; BioTek Instruments, Winooski, VT, USA) at a wavelength of $490 \mathrm{~nm}$. The morphological features of the PC12 cells subjected to the different treatments were analyzed and photographed by phase-contrast microscopy (Nikon eclipse ts100 microscope; Nikon, Tokyo, Japan), at a magnification of x20.

The detection of ROS production was performed using the 2',7'-dichlorofluorescein diacetate (DCFDA)-Cellular ROS Detection Assay kit (Abcam, Cambridge, UK). DCFDA is initially non-fluorescent and is converted by oxidation to DCF, a highly fluorescent compound. DCF was quantified using a CytoFluor Multiwell Plate Reader (Victor 3 Wallac 1420; Perkin Elmer Waltham, MA, USA), with $485 \mathrm{~nm}$ excitation and $538 \mathrm{~nm}$ emission filters. ROS production was expressed as the fluorescence intensity and presented as a percentage relative to the control.

Measurement of enzymatic and non-enzymatic antioxidant levels. The cell cultures $\left(1 \times 10^{6}\right)$ were washed twice in phosphate buffered saline (PBS, pH 7.4) and subsequently centrifuged at $1,890 \times \mathrm{g}$ for $10 \mathrm{~min}$ at $4^{\circ} \mathrm{C}$, producing a cell pellet and the supernatant. Cell pellets were processed for the determination of the enzymatic activity of total glutathione peroxidase (GSH-Px), catalase and total superoxide dismutase (SOD), by adding $500 \mu 1 / 10^{6}$ cells of a hypotonic buffer containing $15 \mathrm{mM} \mathrm{KCl}+1 \mathrm{mM} \mathrm{KH}_{2} \mathrm{PO}_{4}, \mathrm{pH}$ 7.4. After vigorous vortexing for $60 \mathrm{sec}$, the cell suspensions were sonicated at $4^{\circ} \mathrm{C}$ for 3 cycles of $20 \mathrm{sec}$ each with $20 \mathrm{sec}$ intervals between each pulse of sonication. Subsequently, the samples were centrifuged at $20,690 \mathrm{x}$ g for $15 \mathrm{~min}$ at $4^{\circ} \mathrm{C}$ to remove any cell debris. Enzymatic activities were performed spectrophotometrically (using an Agilent 89090A spectrophotometer; Agilent Technologies, Santa Clara, CA, USA) on cell lysates. Total GSH-Px activity was assayed as previously described (15). Briefly, $1 \mathrm{ml}$ of reaction mixture had the following composition: 0.1 M Tris-HCl, $\mathrm{pH}$ 8.0, 4 mM EDTA, $2 \mathrm{mM}$ reduced glutathione (GSH), 1 IU glutathione reductase, $0.3 \mathrm{mM}$ NADPH and $10 \mu \mathrm{l}$ of cell extract. Following $10 \mathrm{~min}$ of incubation at $37^{\circ} \mathrm{C}$, the reaction began by the addition of $70 \mu \mathrm{M}$ tert-butyl hydroperoxide (TBH) and monitored spectrophotometrically (Agilent $89090 \mathrm{~A}$ ) at $340 \mathrm{~nm}$ by following for 10 min NADPH oxidation; blank without TBH and additional blank without cell lysate were used. The millimolar extinction coefficient of $6.3 \times 10^{-3}$ of NADPH was used for the calculation. Catalase activity was examined as previously described (15); the blank reaction mixture ( $1 \mathrm{ml}$ final volume) was composed by $10 \mathrm{mM} \mathrm{KH}_{2} \mathrm{PO}_{4} \mathrm{pH} 7.4$ and $\mathrm{H}_{2} \mathrm{O}_{2} 10 \mathrm{mM}$; the reaction began by the addition of $5 \mu \mathrm{l}$ of cell extract and monitored spectrophotometrically (Agilent 89090A) at $240 \mathrm{~nm}$ by following $\mathrm{H}_{2} \mathrm{O}_{2}$ dismutation. The millimolar extinction coefficient of $3.94 \times 10^{-3}$ of $\mathrm{H}_{2} \mathrm{O}_{2}$ was used for the calculation. Total SOD activity was analyzed as previously described (16). The reaction mixture (1 ml final volume) was formed by $50 \mathrm{mM} \mathrm{KH}_{2} \mathrm{PO}_{4} \mathrm{pH} 7.8$, $10 \mu \mathrm{M}$ oxidized cytochrome $c, 1.25 \mathrm{mM}$ xanthine, $0.006 \mu \mathrm{M}$ xanthine oxidase and $4 \mathrm{mM}$ sodium azide (to inactivate 
catalase). The reaction began by the addition of $20 \mu \mathrm{l}$ of cell extract and monitored spectrophotometrically (Agilent $89090 \mathrm{~A})$ at $550 \mathrm{~nm}$ following the cytochrome $c$ reduction. The millimolar extinction coefficient of $8.4 \times 10^{-3}$ of oxidized cytochrome $c$ was used for the calculation. All enzymatic activities were normalized for the protein content determined by Bradford assay (17) and expressed as IU/mg of protein (1 IU $=1 \mu \mathrm{mol}$ substrated consumed $/ \mathrm{min}$ ). In a different set of experiments, cell pellets, obtained as described above, were treated for the determination of non-enzymatic antioxidant levels with a precipitating solution composed of $\mathrm{CH}_{3} \mathrm{CN} 75 \%$ and $\mathrm{KH}_{2} \mathrm{PO}_{4} 25 \%(10 \mathrm{mM})$ at $\mathrm{pH} 7.4$, and then centrifuged at $20,690 \mathrm{x} \mathrm{g}$ for $15 \mathrm{~min}$ at $4^{\circ} \mathrm{C}$. The supernatants were collected and subjected to 2 chloroform washings in order to obtain an upper aqueous phase that was directly injected onto the HPLC. Each sample was analyzed to determine the concentration of GSH, ascorbate, malondialdehyde (MDA), nitrites and nitrates $\left(\mathrm{NO}_{2}\right.$ and $\left.\mathrm{NO}_{3}\right)$ according to an ion-pairing HPLC method previously set up in our laboratories $(18,19)$. All concentration values were normalized with respect to the protein amount and expressed as nmol/mg protein (17).

Detection of apoptotic cells by Annexin $V$. The cells were seeded at a density of $1 \times 10^{6}$ cells/well on a 24 -well plate and incubated with DHA $24 \mathrm{~h}$ prior to the exposure to $\mathrm{H}_{2} \mathrm{O}_{2}$ ( $300 \mu \mathrm{M}$ for $24 \mathrm{~h}$ ). The medium was then aspirated, and the cells were washed with PBS. After the cells were incubated at room temperature, for $15 \mathrm{~min}$ in a dark room with Annexin V-FITC (TACS Annexin V kit; Trevigen, Gaithersburg, MD, USA). The cells were then examined under a fluorescence microscope (Nikon Eclipse TE300 Inverted Fluorescence Microscope; Nikon) with a x20 objective lens.

Detection of $\Delta \Psi m . \Delta \Psi \mathrm{m}$, an early marker of the induction of apoptosis, was assessed using the Mitolight ${ }^{\mathrm{TM}}$ Apoptosis Detection kit (APT142; Chemicon International, Temecula, CA, USA). The cells ( $4 \times 10^{4}$ cells/well in a PLL-coated black-bottom 96-well plate) (treated as described above) were incubated with $100 \mu \mathrm{l}$ of prediluted Mitolight ${ }^{\mathrm{TM}}$ dye solution for $15 \mathrm{~min}\left(37^{\circ} \mathrm{C}, 5 \% \mathrm{CO}_{2}, 95 \%\right.$ air $)$. In healthy cells, the dye accumulates and aggregates in the mitochondria, giving off a bright red fluorescence $(\lambda e m=585 \mathrm{~nm})$. In apoptotic cells with an altered $\Delta \Psi \mathrm{m}$, the dye in monomeric form remains in the cytoplasm, fluorescing green $(\lambda e m=530 \mathrm{~nm})$ and thus providing a ready discrimination between apoptotic and non-apoptotic cells. The fluorescence intensities were measured with a Victor multilabel plate reader (PerkinElmer, Waltham, MA, USA) at an excitation wavelength $485 \mathrm{~nm}$ and an emission wavelength $530 \mathrm{~nm}$ to monitor apoptotic cells and $585 \mathrm{~nm}$ for healthy cells, respectively. The data were expressed as a fluorescence ratio (585/530) representative of the arbitrary $\Delta \Psi \mathrm{m}$. The cells were also observed using a Nikon Eclipse TE300 Inverted Fluorescence Microscope (Nikon) (data not shown).

RNA isolation and semi-quantitative PCR. Total RNA was isolated using the SV Total RNA Isolation System (Promega srl). The RNA concentration was evaluated by spectrophotometric reading at 280 and $260 \mathrm{~nm}$. Total RNA was used for first strand cDNA synthesis with the HyperScript, First strand Synthesis kit and Oligo-dT, as random primer (GeneAll Biotechnology Co. Ltd., Seoul, Korea). PCR was performed with about 150 ng of cDNA using PCRBIO Classic Taq (PCR Biosystems Ltd., London, UK). The following primer sequences were used for amplification: Actin $\beta$ ( $\beta$-actin) forward, 5'-TGC TATGTTGCCCTAGACTTCG-3' and reverse, 5'-GTTGGC ATAGAGGTCTTTACGG-3' (240 bp); Bax forward, 5'-GCA GGGAGGATGGCTGGGGAG-3' and reverse, 5'-TCCAGA CAAGCAGCCGCTCACG-3' (352 bp); Bcl2 forward, 5'-CAC CCCTGGCATCTTCTCCT-3' and reverse, 5'-GTTGACGCT CCCCACACACA-3' (349 bp); NFE2L2 forward, 5'-GCC AGCTGAACTCCTTAGAC-3' and reverse, 5'-GATTCG TGCACAGCAGCA-3' (466 bp); and HO-1 forward, 5'-GAA ACAAGCAGAACCCAGTC-3' and reverse, 5'-AGAGGT CACCCAGGTAGCG-3' (225 bp).

The experimental protocols, in accordance with the conditions reported in the literature $(14,20)$ and slightly modified, were as follows: An initial denaturation for $3 \mathrm{~min}$ at $95^{\circ} \mathrm{C}$; amplification for 21 ( $\beta$-actin), 20 (NFE2L2), 30 (HO-1) and 40 cycles (Bax and $\mathrm{Bcl} 2$ ) of denaturation, $15 \mathrm{sec}, 95^{\circ} \mathrm{C}$, annealing: $15 \mathrm{sec}$, at $61^{\circ} \mathrm{C}\left(\beta\right.$-Actin), $58^{\circ} \mathrm{C}(\mathrm{NFE} 2 \mathrm{~L} 2), 55^{\circ} \mathrm{C}$ $(\mathrm{HO}-1), 60^{\circ} \mathrm{C}(\mathrm{Bax}), 59^{\circ} \mathrm{C}(\mathrm{Bcl} 2)$ and elongation at $72^{\circ} \mathrm{C}$ for $1 \mathrm{~min}$; and a final elongation for $10 \mathrm{~min}$ at $72^{\circ} \mathrm{C}$. The PCR products were then analyzed by $1.5 \%$ agarose gel electrophoresis in TBE1X buffer. Image acquisition and product analysis were made using Bio-Rad imaging systems with Quantity One ${ }^{\circledR} 1-\mathrm{D}$ analysis software.

Bax, Bcl2, NFE2L2 and HO-1 intracellular detection. The detection of intracellular $\mathrm{Bax}, \mathrm{Bcl} 2$ and NFE2L2 proteins was performed using colorimetric cell-based ELISA kits from Assay Biotechnology (Sunnyvale, CA, USA) for Bax (cat. no. CB5066) and for Bcl2 (cat. no. CB5068) and from LSBio/LifeSpan Biosciences, Inc. (Seattle, WA, USA) for NFE2L2 (cat. no. LS-F2192). In brief, the cells were seeded at $3 \times 10^{4}$ cells/well in a 96-well dish and treated according to the experimental protocol; at the end of the experiment, the cells were fixed with $4 \%$ formaldehyde. Successively, quenching buffer, blocking buffer and finally primary antibodies (rabbit anti-Bax, rabbit anti-Bcl2, rabbit anti-NFE2L2 according to the experimental design, or mouse anti-GAPDH; the latter used as a positive internal control) were added followed by incubation overnight at $4^{\circ} \mathrm{C}$. All primary antibodies were diluted 1:100 according to the Technical Manual (the antibodies were included with the kit). Following this overnight incubation, the secondary antibodies (included with the kit; anti-rabbit IgG for Bax, Bcl2 and NFE2L2; Anti-mouse IgG for GADPH) conjugated to peroxidase were added and subsequently the samples were read with a microplate reader (BioTek $^{\mathrm{TM}}$ Elx800 -Box 998; BioTek Instruments) [optical density (OD) at $450 \mathrm{~nm}$ ]. The positive controls were performed in the same plates with the target experiments. All values obtained, normalized to GAPDH OD450, were expressed as a percentage relative to the control (untreated cells).

For the intracellular detection of $\mathrm{HO}-1$, the PC12 cells were examined using a kit sandwich ELISA (Abcam, Cambridge, UK, cat. no. ab213968). The ELISA was performed according to the manufacturer's protocol. Briefly, $1 \times 10^{6}$ cells, after treating, were lysed (using $1 \mathrm{ml}$ extraction reagent, provided with the kit, supplemented with protease inhibitors) and 


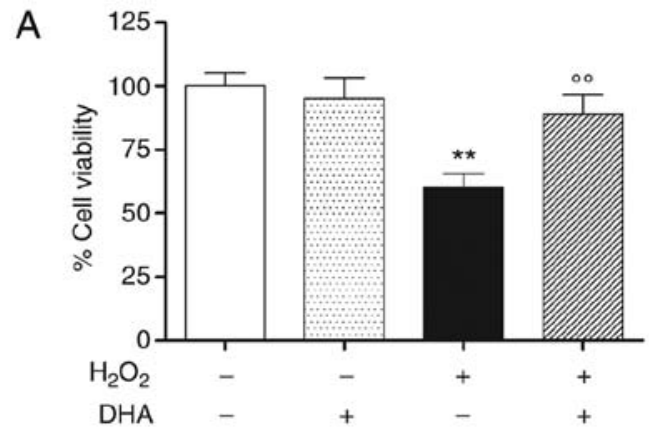

B
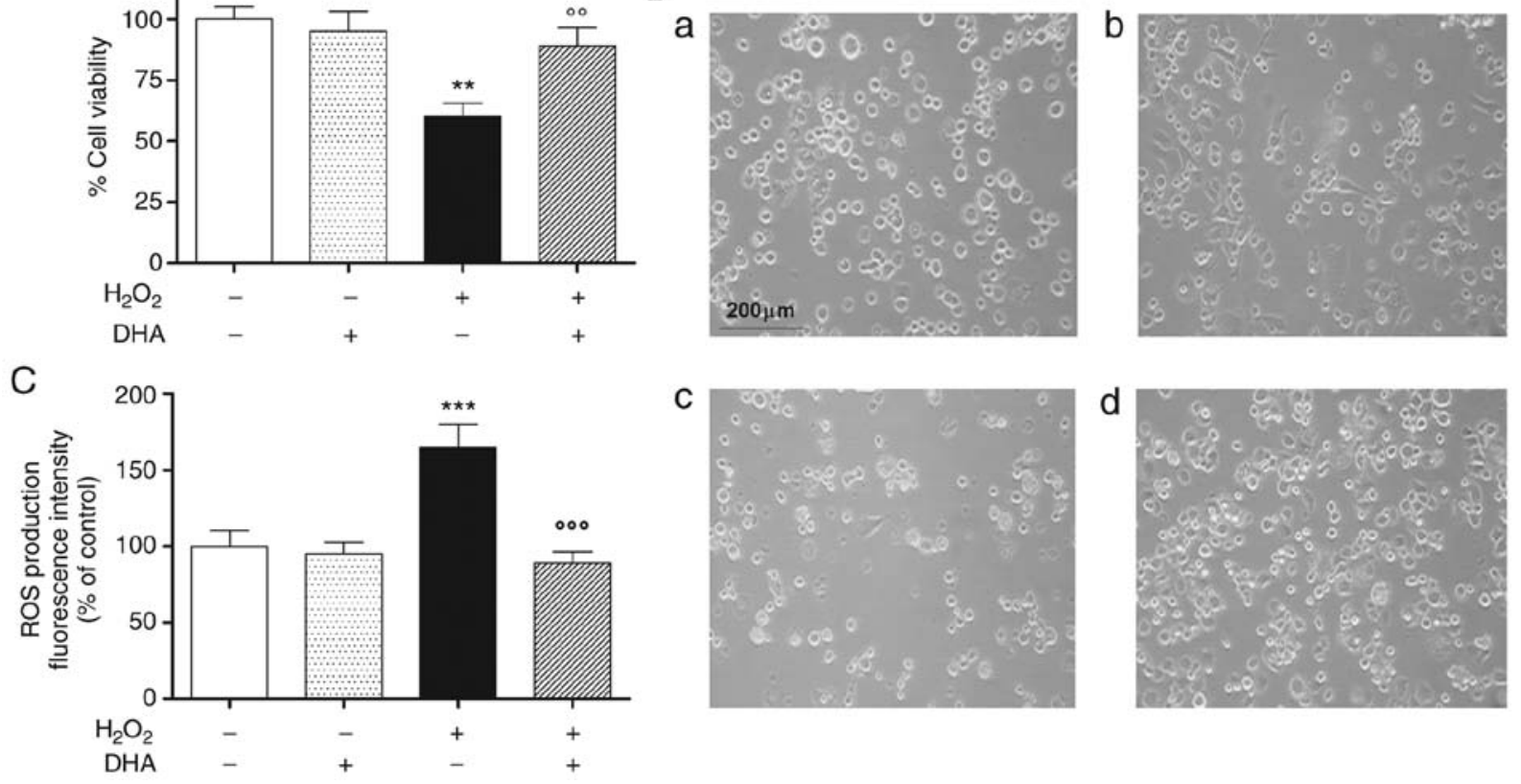

Figure 1. (A) PC12 cell viability following pre-treatment with $60 \mu \mathrm{M}$ DHA (for $24 \mathrm{~h}$ ) under baseline conditions and under $\mathrm{H}_{2} \mathrm{O}_{2}$ stimulation. (B) Morphology of PC12 cells in the same experimental paradigm observed by phase-contrast microscopy: Panel a, controls; panel b, cells treated with DHA alone; panel c, cells exposed to $\mathrm{H}_{2} \mathrm{O}_{2}$ alone; panel d, cells pre-treated for $24 \mathrm{~h}$ with DHA and successively with $\mathrm{H}_{2} \mathrm{O}_{2}$. (C) ROS production (expressed as fluorescence intensity) in PC12 cells following pre-treatment with $60 \mu \mathrm{M}$ DHA (for $24 \mathrm{~h}$ ) under basal conditions and after $\mathrm{H}_{2} \mathrm{O}_{2}$ stimulation. For the experimental details, please see the Materials and methods section. Data are expressed as a percentage relative to the untreated cells (control=100\%) and are presented as the means \pm SEM of 7 replicates per group. ${ }^{* *} \mathrm{P}<0.01$ and ${ }^{* * *} \mathrm{P}<0.001$ vs. control; ${ }^{\circ 0} \mathrm{P}<0.01$ and ${ }^{\circ 0 \circ} \mathrm{P}<0.001$ vs. $\mathrm{H}_{2} \mathrm{O}_{2}$ alone, respectively. DHA, docosahexaenoic acid.

centrifuged at $10,000 \mathrm{xg}$, at $4^{\circ} \mathrm{C}$ for $10 \mathrm{~min}$. The collected supernatants, following protein measurement and normalization, were plated into plates precoated (with monoclonal anti-rat HO-1 antibody, ready to use). HO-1 immobilization was detected with a specific polyclonal antibody and successively with a secondary antibody (Rat HO-1, ready to use) conjugated to the peroxidase. The intensity of the color was measured on a microplate reader (BioTek ${ }^{\mathrm{TM}}$ Elx800 -Box 998; BioTek Instruments) at $450 \mathrm{~nm}$. To generate the standard curve, provided rat $\mathrm{HO}-1$ standard $(5 \mu \mathrm{g} / \mathrm{ml})$ was stepwise diluted $(25,12,5,6,5,3,13,1,56,0,78,0,39$ and $0 \mathrm{ng} / \mathrm{ml})$ and the readers were plotted (using a linear scale) and thus: Concentrations ( $\mathrm{ng} / \mathrm{ml}$ ) on the $\mathrm{x}$-axis and absorbance measurements on the y-axis. HO-1 concentrations from the samples were quantified by interpolating the absorbance readings from a standard curve. The data were expressed as a percentage relative to the control (untreated cells).

Statistical analysis. Each experiment was repeated at least 3 times, separately. All the results are presented as the means \pm SEM of $(n)$ replicates per experimental group. Data were subsequently analyzed by one-way ANOVA, followed by the post hoc Newman-Keuls test for comparisons between group means, using a Prism ${ }^{\mathrm{TM}}$ computer program (GraphPad, San Diego, CA, USA). Differences were considered statistically significant at $\mathrm{P}<0.05$.

\section{Results}

DHA pre-treatment attenuates $\mathrm{H}_{2} \mathrm{O}_{2}$-induced cell death and oxidative damage. In preliminary experiments, the protective effects of DHA against $\mathrm{H}_{2} \mathrm{O}_{2}$-induced oxidative stress were investigated in the pheochromocytoma cell line, PC12, by MTS assay. The cells were pre-treated with physiological concentrations of DHA $(60 \mu \mathrm{M})$ for $24 \mathrm{~h}$ and then treated with $\mathrm{H}_{2} \mathrm{O}_{2}$ for a further $24 \mathrm{~h}$, with the exception of the control groups. A significant and consistent decrease (approximately 40\%) in cell viability was observed following 24 h of exposure to $\mathrm{H}_{2} \mathrm{O}_{2}$. Under these conditions, pre-treatment with DHA was able to antagonize the effects of $\mathrm{H}_{2} \mathrm{O}_{2}$. DHA alone did not affect cellular viability in the same experimental paradigm (Fig. 1A).

The cell viability data were also confirmed by subsequent morphological experiments conducted in the same experimental paradigm (Fig. 1B). The number of cells was markedly reduced and many of these had a rounded appearance following exposure to $300 \mu \mathrm{M} \mathrm{H}_{2} \mathrm{O}_{2}$ (Fig. 1B, panel c), compared to the controls and to cells treated with DHA alone (Fig. 1B, panels a and b); pre-treatment with DHA exerted potent protective effects against $\mathrm{H}_{2} \mathrm{O}_{2}$-induced oxidative damage (Fig. 1B, panel D).

A second series of experiments were performed to ascertain whether the protective effects observed post-DHA treatment were associated with the reduction of ROS production and oxidative damage. Under these conditions, pre-treatment (24 h) with DHA was able to reduce ROS production induced by $\mathrm{H}_{2} \mathrm{O}_{2}$, while it was not able to alter the intracellular ROS levels under baseline conditions (Fig. 1C).

Additional experiments were performed to investigate the biochemical mechanisms underlying the antioxidant effects of DHA: Enzymatic (SOD, catalase and GSH-Px) and non-enzymatic (GSH and ascorbic acid) antioxidants, an indicator of lipid peroxidation (MDA) and nitrates and nitrites 
Table I. Intracellular levels of enzymatic antioxidants in PC12 cells in both the presence and absence of DHA under different experimental conditions.

\begin{tabular}{lcccc}
\hline Compound & Control mean \pm SEM $(\mathrm{n})$ & DHA mean \pm SEM $(\mathrm{n})$ & $\mathrm{H}_{2} \mathrm{O}_{2}$ mean \pm SEM $(\mathrm{n})$ & DHA $+\mathrm{H}_{2} \mathrm{O}_{2}$ mean \pm SEM $(\mathrm{n})$ \\
\hline SOD & $42.20 \pm 2.291(5)$ & $58.72 \pm 2.348(5)^{\mathrm{b}}$ & $25.20 \pm 2.652(5)^{\mathrm{a}}$ & $40.00 \pm 6.611(5)^{\mathrm{c}}$ \\
CAT & $23.42 \pm 3.149(5)$ & $19.278 \pm 1.332(5)$ & $10.890 \pm 0.599(5)^{\mathrm{b}}$ & $12.036 \pm 0.579(5)$ \\
GSH-Px & $18.36 \pm 1.592(5)$ & $36.55 \pm 4.759(5)^{\mathrm{b}}$ & $9.15 \pm 0.913(5)^{\mathrm{a}}$ & $25.69 \pm 2.671(5)^{\mathrm{d}}$ \\
\hline
\end{tabular}

Data are expressed as $\mathrm{U} / \mathrm{mg}$ protein (see Materials and methods section), and the means \pm 1 SEM of 5 replicates per group are shown. ${ }^{\mathrm{a}} \mathrm{P}<0.05$ and ${ }^{b} \mathrm{P}<0.01$ vs. control; ${ }^{c} \mathrm{P}<0.05$ and ${ }^{d} \mathrm{P}<0.01$ vs. $\mathrm{H}_{2} \mathrm{O}_{2}$ alone. SOD, superoxide dismutase; CAT, catalase; GSH-Px, glutathione peroxidase.

Table II. Intracellular levels of GSH, ascorbic acid, MDA, nitrate and nitrite in PC12 cells in both the presence and absence of DHA under different experimental conditions.

\begin{tabular}{lcccc}
\hline Compound & Control mean \pm SEM (n) & DHA mean \pm SEM (n) & $\mathrm{H}_{2} \mathrm{O}_{2}$ mean \pm SEM $(\mathrm{n})$ & DHA $+\mathrm{H}_{2} \mathrm{O}_{2}$ mean \pm SEM (n) \\
\hline GSH & $55.25 \pm 5.2(5)$ & $86.65 \pm 6.8(5)^{\mathrm{b}}$ & $52.47 \pm 5.3(5)$ & $93.11 \pm 7.1(5)^{\mathrm{b}, \mathrm{d}}$ \\
Ascorbic acid & $2.25 \pm 0.52(5)$ & $2.29 \pm 0.7(5)$ & $0.45 \pm 0.09(5)^{\mathrm{a}}$ & $0.65 \pm 0.1(5)^{\mathrm{a}}$ \\
MDA & $0.01 \pm 0.001(5)$ & $0.02 \pm 0.001(5)$ & $0.03 \pm 0.009(5)^{\mathrm{a}}$ & $0.01 \pm 0.002(5)^{\mathrm{c}}$ \\
Nitrate & $7.45 \pm 1.0(5)$ & $9.81 \pm 1.3(5)$ & $8.89 \pm 0.9(5)$ & $9.48 \pm 1.2(5)$ \\
Nitrite & $1.28 \pm 0.8(5)$ & $2.00 \pm 0.6(5)$ & $2.91 \pm 0.8(5)$ & $2.15 \pm 0.8(5)$ \\
\hline
\end{tabular}

Data are expressed as nmol/mg protein (see Materials and methods section), and the means \pm 1 SEM of 5 replicates per group are shown. ${ }^{\mathrm{a}} \mathrm{P}<0.05$ and ${ }^{\mathrm{b}} \mathrm{P}<0.01$ vs. control; ${ }^{\mathrm{c}} \mathrm{P}<0.05$ and ${ }^{\mathrm{d}} \mathrm{P}<0.01$ vs. $\mathrm{H}_{2} \mathrm{O}_{2}$ alone. $\mathrm{GSH}$, reduced glutathione; MDA, malondialdehyde.

were measured in the presence or absence of DHA under basal conditions and in response to oxidative stress. The mean concentration levels of enzymatic antioxidants were markedly lower in the cells exposed to $\mathrm{H}_{2} \mathrm{O}_{2}$ than in the controls (Table I). DHA pre-treatment increased the intracellular levels of SOD and GSH-Px in a significant manner under basal conditions and following $\mathrm{H}_{2} \mathrm{O}_{2}$-induced oxidative stress (Table I). The catalase levels were increased by DHA pre-treatment under oxidative stress conditions compared to $\mathrm{H}_{2} \mathrm{O}_{2}$ exposure alone, although the difference was not statistically significant. The catalase basal intracellular concentrations remained unaltered $(\mathrm{P}>0.05)$ in the presence of DHA (Table I).

In addition, Table II shows the effects of DHA pre-treatment on GSH, ascorbic acid, MDA, nitrates and nitrites under basal and oxidative conditions. It was observed that: i) DHA significantly increased the GSH levels both under baseline conditions and in the presence of $\mathrm{H}_{2} \mathrm{O}_{2}$; ii) DHA increased the intracellular concentrations of ascorbic acid and decreased those of MDA in a statistically significant manner only in the presence of $\mathrm{H}_{2} \mathrm{O}_{2}$; iii) the intracellular levels of nitrates and nitrites remained unaltered following pre-treatment with DHA under both experimental conditions. The results obtained above support the hypothesis that DHA exerts antioxidant effects on $\mathrm{H}_{2} \mathrm{O}_{2}$-exposed $\mathrm{PC}-12$ cells by modulating the levels of antioxidant enzymes and non-enzymatic scavengers, which regulate the levels of ROS.

DHA pre-treatment attenuates oxidative-stress-induced apoptosis. PC12 cell morphology was observed by fluorescence microscopy using an Annexin $\mathrm{V}$ staining assay to detect apoptotic cells following pre-treatment with DHA in the presence or absence of oxidative damage. As shown in Fig. 2A, the apoptosis of the cells pre-treated with DHA was visibly decreased compared with that of the cells exposed to $\mathrm{H}_{2} \mathrm{O}_{2}$ alone. The process of apoptosis is strongly associated with the loss of $\Delta \Psi \mathrm{m}$ in different cells. Indeed, the opening of the mitochondrial permeability transition pore induces the depolarization of the transmembrane potential, and the release of apoptotic factors and the loss of oxidative phosphorylation. Consequently, in this study, in order to determine whether DHA inhibits $\mathrm{H}_{2} \mathrm{O}_{2}$-induced apoptosis related to the mitochondrial pathway, $\mathrm{PC} 12$ cells were pre-treated with DHA and exposed to $\mathrm{H}_{2} \mathrm{O}_{2}$ to induce mitochondrial dysfunction. The $\Delta \Psi \mathrm{m}$ of the cells was reduced with $\mathrm{H}_{2} \mathrm{O}_{2}$ alone ( $60 \%$ less than the control), but was enhanced follwoing pre-treatment (24 h) with DHA in a statistically significant manner (Fig. 2B). These results confirmed our hypothesis that DHA is able to inhibit $\mathrm{H}_{2} \mathrm{O}_{2}$-induced mitochondrial dysfunction in $\mathrm{PC} 12$ cells.

To confirm this hypothesis further, the subsequent experiments were aimed to investigate the effects of DHA pre-treatment on $\mathrm{Bax}$ and $\mathrm{Bcl} 2$ gene and protein expression levels. As shown (in Fig. 2C and D, left panel), the expression of the pro-apoptotic gene, Bax, was increased in the $\mathrm{H}_{2} \mathrm{O}_{2}$-exposed cells, while DHA pre-treatment markedly reduced its expression. On the contrary, the expression of anti-apoptotic gene, $\mathrm{Bcl} 2$, was decreased following $\mathrm{H}_{2} \mathrm{O}_{2}$ exposure, while the gene expression was reversed in the cells pre-treated with DHA (Fig. 2C and D, right panel). The same trend was also observed for the protein levels of Bax and Bcl2 in the same experimental paradigm (Fig. 2E). 
A
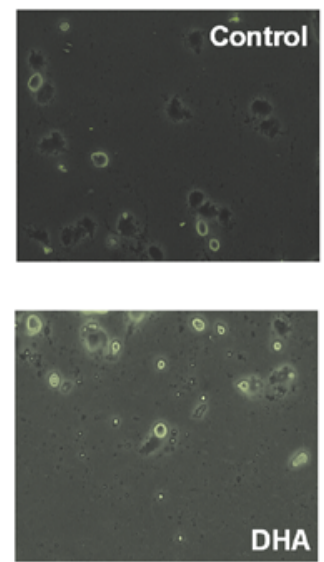
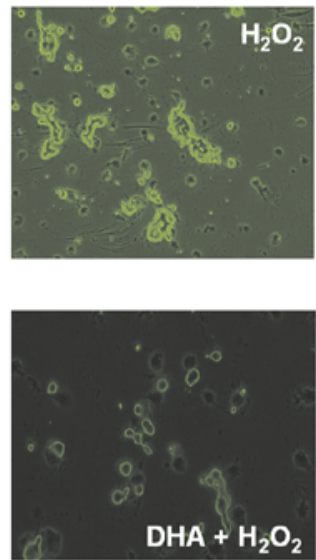

B

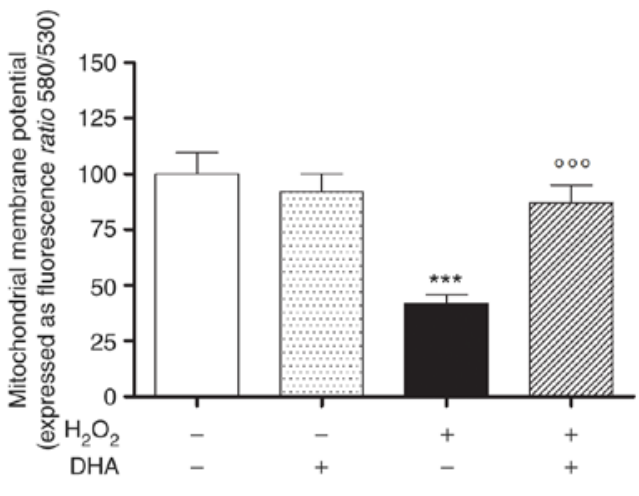

C

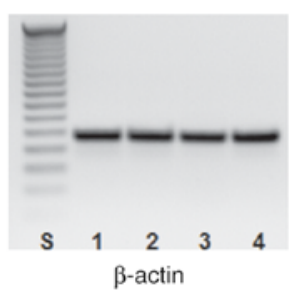

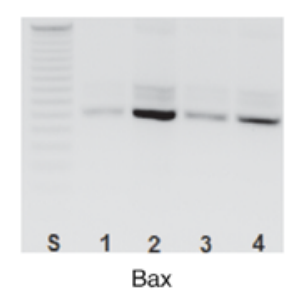

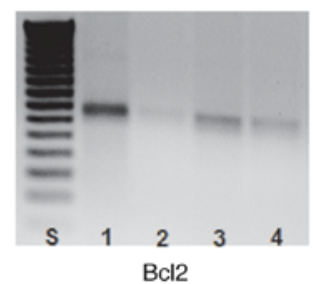

D

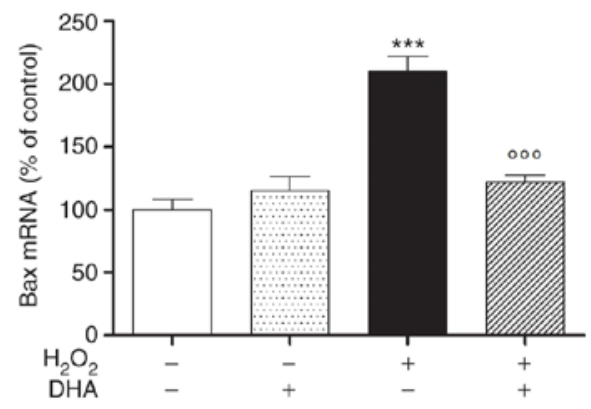

E

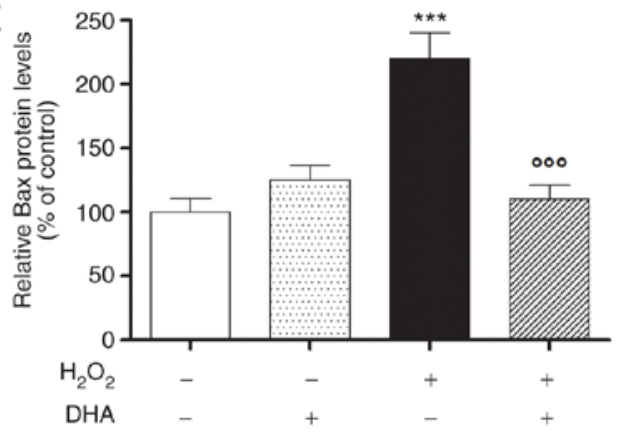

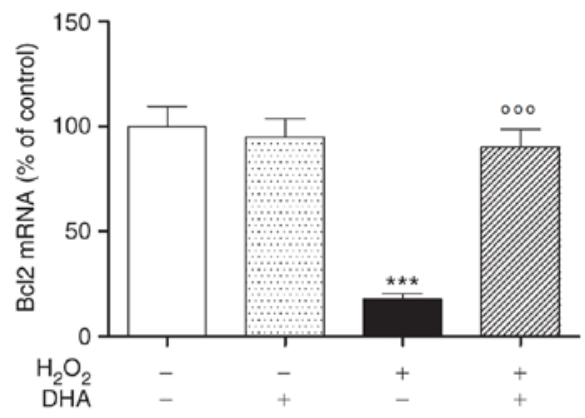

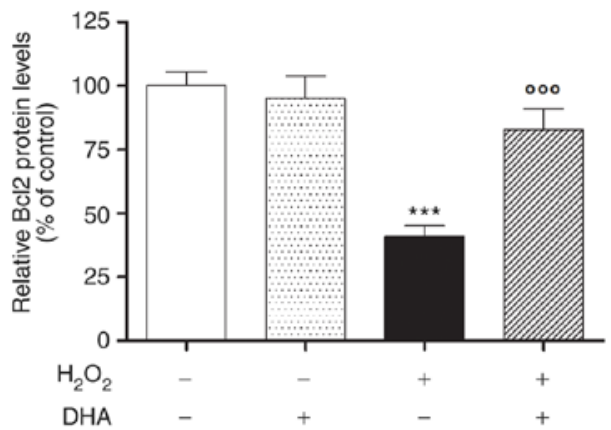

Figure 2. DHA and apoptosis. (A) Fluorescent staining for the detection of the apoptosis of PC12 cells under basal conditions (control) and following treatment with: i) $\mathrm{H}_{2} \mathrm{O}_{2}\left(300 \mu \mathrm{M} ; 24 \mathrm{~h}\right.$ of treatment); ii) DHA $\left(60 \mu \mathrm{M} ; 24 \mathrm{~h}\right.$ of treatment); iii) DHA plus $\mathrm{H}_{2} \mathrm{O}_{2}$ (cells pre-treated for $24 \mathrm{~h}$ with DHA and subsequently exposed to $\mathrm{H}_{2} \mathrm{O}_{2}$ for a further $24 \mathrm{~h}$ ). Apoptotic cells were detected by Annexin staining assay. Representative images from 3 independent experiments are shown. (B) The mitochondrial membrane potential $(\Delta \Psi \mathrm{m})$ was measured in PC12 cells by the Mitolight Apoptosis detection kit (see the Materials and methods section for details). The fluorescence intensities were measured at an emission wavelength $580 \mathrm{~nm}$ to monitor aggregated molecules (apoptotic cells) and $530 \mathrm{~nm}$ for monomer (healthy cells), respectively. Data are expressed as fluorescence intensities ratio (580/530) and reported as a percentage of the control. The means \pm SEM of 3 determinations in double are shown. (C) Agarose gels representing the mRNA expression levels of $\beta$-actin (housekeeping gene, $240 \mathrm{bp}$ ), Bax (352 bp) and Bcl2 (349 bp). Lane S, DNA ladder (50 bp); lane 1, untreated cells; lane 2, cells exposed to $\mathrm{H}_{2} \mathrm{O}_{2}$ alone; lane 3, cells treated with DHA alone; lane 4, cells pre-conditioned for $24 \mathrm{~h}$ with DHA prior to exposure to $\mathrm{H}_{2} \mathrm{O}_{2}$ for a further $24 \mathrm{~h}$. (D) Bax (left panel) and Bcl2 (right panel) densitometric analysis of the gels in (C) The density of the gel bands was divided by $\beta$-actin and the results were expressed as a percentage of the control band density. Results are from 3 independent experiments performed in duplicate. (E) Effects of pre-treatment with DHA (24 h) on Bax (left panel) and Bcl2 (right panel) protein levels in PC12 cells under baseline conditions and under $\mathrm{H}_{2} \mathrm{O}_{2}$ stimulation. Bax and Bcl2 protein levels were detected by ELISA assay and normalized against GADPH (details in Materials and methods section). Results are from 2 independent experiments, each including 3 replicates per experimental group. The data in the figure are presented as the means $\pm \mathrm{SEM} .{ }^{* * * *} \mathrm{P}<0.001$ vs. controls; ${ }^{\circ 00} \mathrm{P}<0.001$ vs. $\mathrm{H}_{2} \mathrm{O}_{2}$ alone. DHA, docosahexaenoic acid.

DHA protective effect involves the NFE2L2 antioxidant pathway. To elucidate the plausible signal transduction pathways involved in the DHA-mediated protective effects, we examined the involvement of NFE2L2, the principal transcription factor that regulates the basal and inducible expression of a number of antioxidant genes. In order to provide direct 
A

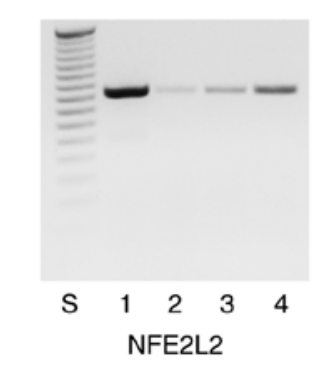

B

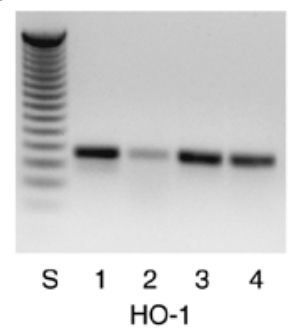

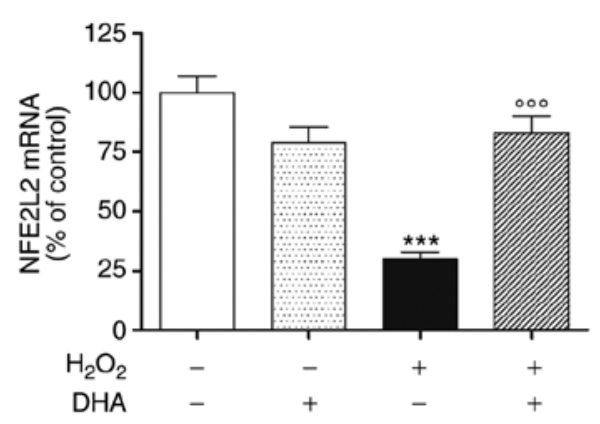

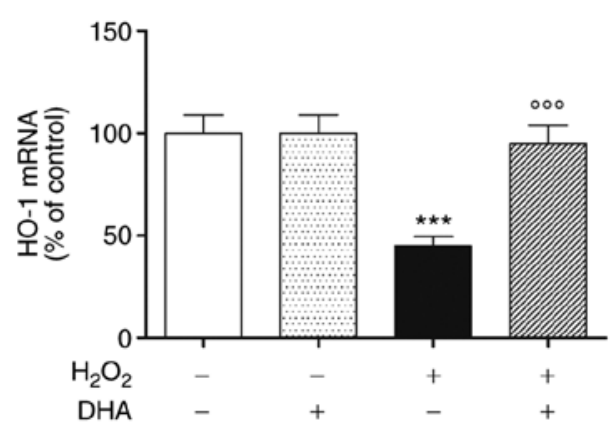

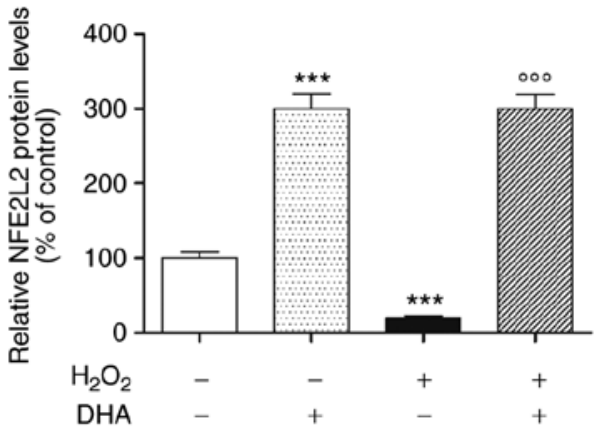

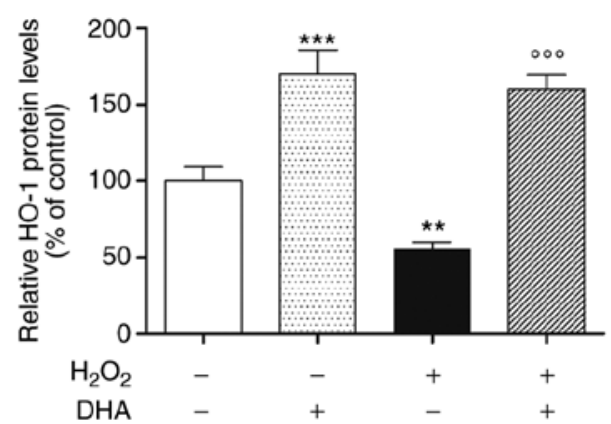

Figure 3. Agarose gels representing (A) the mRNA expression levels of NFE2L2 (466 bp) and (B) HO-1 (225 bp) in PC12 cells. Lane S, DNA ladder (50 bp); lane 1, untreated cells; lane 2, cells exposed to $\mathrm{H}_{2} \mathrm{O}_{2}$ alone; lane 3, cells treated with DHA alone; lane 4, cells pre-conditioned for 24 h with DHA prior to exposure to $\mathrm{H}_{2} \mathrm{O}_{2}$ for a further $24 \mathrm{~h}$. The density of the gel bands was divided by that of $\beta$-actin (Fig. 2) and expressed as a percentage of the control band density. All results are from 3 independent experiments. Data are presented as the means $\pm \mathrm{SEM}$. ${ }^{* *} \mathrm{P}<0.01$ and ${ }^{* * * *} \mathrm{P}<0.001$ vs. control; ${ }^{\circ 00} \mathrm{P}<0.001$ vs. $\mathrm{H}_{2} \mathrm{O}_{2}$ alone. DHA, docosahexaenoic acid; NFE2L2, nuclear factor (erythroid-derived 2)-like 2; HO-1, heme-oxygenase-1.

evidence of the involvement of NFE2L2 activation, the PC12 cells were pre-treated with DHA for $24 \mathrm{~h}$, followed by exposure to $\mathrm{H}_{2} \mathrm{O}_{2}$ for an additional $24 \mathrm{~h}$. We observed in our experimental paradigm that $\mathrm{H}_{2} \mathrm{O}_{2}$ markedly downregulated NFE2L2 mRNA expression, which was antagonized by pre-treatment with DHA (Fig. 3A, left and middle panels). Notably, DHA was effective only in the presence of oxidative damage; in fact, pre-treatment with DHA alone did not stimulate NFE2L2 gene expression, but rather decreased it (Fig. 3A, left and middle panels). The results obtained were also confirmed by subsequent experiments conducted to determine the NFE2L2 protein intracellular levels. In particular, the NFE2L2 protein levels increased $>3$-fold following DHA pre-treatment both under basal conditions and following $\mathrm{H}_{2} \mathrm{O}_{2}$-induced oxidative damage (Fig. 3A, right panel).

The transcriptional activation of NFE2L2 evokes the activation of a series of phase II detoxifying enzymes, including HO-1, which is able to protect cells against oxidative damage. Therefore, to further investigate whether DHA-induced NFE2L2 activation modulate in turn HO-1, we examined the effects of DHA pre-treatment on the activation of the NFE2L2/HO-1 pathway in PC12 cells in same experimental paradigm. The intracellular mRNA expression and protein levels of HO-1 were markedly decreased to an estimated $50 \%$ following exposure to $\mathrm{H}_{2} \mathrm{O}_{2}$ in comparison to the untreated cells. The observed effect was markedly inhibited by DHA pre-treatment $(24 \mathrm{~h})$, which increased the mRNA expression and protein levels of HO-1 to values equal or higher than those observed in the untreated cells, respectively (Fig. 3; pan B). Under baseline conditions, the DHA alone significantly increased the HO-1 protein levels, while it had no effect on the mRNA expression of the enzyme (Fig. 3B).

\section{Discussion}

The wide variety of physiopathological relapses, generated in the organism by redox imbalance, can explain why oxidative stress has been implicated in the pathogenesis and complications of a number of neurodegenerative diseases. Therefore, evaluating oxidative stress and ROS (which are considered to be mediators of oxidative damage) levels and attempting to counteract the progression of damage, can be limited. A number of edible natural compounds have been shown to modulate ROS production and consequently, oxidative damage. DHA, a dietary fat, is a representative n-3 PUFA, which has a wide array of health beneficial effects; of note are its effects at the central nervous system level (21-23), as it has been shown to decrease the risk of developing Alzheimer's disease (24). Although the protective effects of DHA have long been associated with the modification of cell membrane fluidity, there is new evidence to suggest that the action of this fatty acid may be attributed to the modulation of anti-inflammatory gene expression and anti-oxidative pathways $(25,26)$. However, the biochemical mechanisms underlying the protective effects of DHA remain unclear. Thus, in the present study, we focused on investigating the potential protective effects of DHA at physiological concentrations against $\mathrm{H}_{2} \mathrm{O}_{2}$-induced oxidative damage in rat pheochromocytoma cells (PC12), exploring cell viability, the oxidation potential, and the anti-apoptotic and antioxidant effects.

$\mathrm{H}_{2} \mathrm{O}_{2}$ is currently the most widely used experimental model for simulating oxidative stress. In fact, $\mathrm{H}_{2} \mathrm{O}_{2}$ belongs to ROS and is potentially harmful to cell viability as it damages different cellular targets. As expected, $\mathrm{H}_{2} \mathrm{O}_{2}$ was found to be toxic to cells in our experimental model, leading to a marked decrease in the overall cellular viability, an increase in ROS 
levels and to the activation of the apoptotic cascade. These effects were antagonized by treatment with DHA for $24 \mathrm{~h}$ prior to exposure to $\mathrm{H}_{2} \mathrm{O}_{2}$. Pre-treatment with DHA increased the antioxidant activity by an increase in cell viability and a reduction in ROS levels, thus protecting the cells against oxidative stress-induced cell damage. The cells have integrated antioxidant systems, which include enzymatic and non-enzymatic antioxidants, that are usually effective in blocking the noxious effects of ROS (27). However, under pathological conditions, these systems may be insufficient (28). In this study, we demonstrated that DHA was able to reverse the $\mathrm{H}_{2} \mathrm{O}_{2}$-induced intracellular levels of a few of these antioxidants (SOD, catalase, GSH-Px, GSH, ascorbic acid and MDA). Furthermore, we observed a clear reduction in the apoptotic signals by DHA, which exerted both a protective effect at the mitochondrial level and played a regulatory role in the modulation of Bax- and Bcl2-mediated apoptosis, both negative and positive. Overall, these findings suggest that DHA may be able to protect the cells against stress-induced apoptosis, mainly via the protection of the mitochondrial pathway.

Notably, it has been recently identified that NFE2L2 is able to activate antioxidant cellular defences and to inhibit apoptotic pathways (29). NFE2L2 is a regulator of cellular resistance against oxidants. It controls the gene expression of a large variety of antioxidant/cytoprotective enzymes and detoxification phase II enzymes, regulating the physiological and pathophysiological outcomes of oxidant exposure. In fact, oxidative stress dissociates NFE2L2 from its cytoplasmic inhibitor, Kelch-like ECH-associated protein 1 (KEAP1), promoting its translocation into the nucleus, where it binds to AREs leading to the transcriptional activation of antioxidant/cytoprotective enzymes, such as HO-1, SOD and subunits which are necessary for GSH biosynthesis (30). In particular, HO-1 antagonizes oxidative stress by activating the expression of SOD (31) and through the degradation of the pro-oxidant, heme, leading to the production of bilirubin and $\mathrm{CO}$, that are important antioxidants (32-34). Moreover, under stress conditions, NFE2L2 directly prevents apoptosis by activating Bcl-2, inhibiting Bax and through the activation of p62, and reduces mitochondrial dysfunctions. The findings obtained in this study coincide with the aforementioned: We observed a significant increase in the cellular levels of NFE2L2 following pre-incubation with DHA in our experimental model, and we thus hypothesized that this PUFA can increase the levels of key antioxidant enzymes, such as SOD, GSH-Px and HO-1, as well as modulate apoptotic pathways.

In this study, we measured the level of NFE2L2 in the whole cell, based on previously published data $(35,36)$ demonstrating that when PC12 cells are subjected to oxidative stress, NFE2L2 is exclusively present at nuclear level. However the observed mechanism may be associated mainly with a direct action of DHA on availability of NFE2L2 in monomeric form, rather than on gene expression, as evidenced by the data on gene expression and protein levels of NEF2L2. In fact, the mRNA expression levels of both NFE2L2 and HO-1 remained almost similar to the controls following pre-treatment with DHA, in the presence of $\mathrm{H}_{2} \mathrm{O}_{2}$ but, above all, under basal conditions. This direct action at the post-transcriptional level could also explain the directness with which DHA, after $24 \mathrm{~h}$ of pre-treatment, counteracted the oxidizing and apoptotic effects exerted by $\mathrm{H}_{2} \mathrm{O}_{2}$. Notably, while the exposure of cells to $\mathrm{H}_{2} \mathrm{O}_{2}$ is a well-established experimental model of oxidative damage, the effects of $\mathrm{H}_{2} \mathrm{O}_{2}$ on NEF2L2 activation and the expression of its downstream gene products remains controversial and unclear. In fact, on the one hand, it has been shown that $\mathrm{H}_{2} \mathrm{O}_{2}$ stabilizes and activates NEF2L 2 by the oxidation and de-activation of KEAP1 (35), while on the other hand, it has been observed that exposure to $\mathrm{H}_{2} \mathrm{O}_{2}$ reduces the mRNA and protein levels of NEF2L2 (35-41), hypothesizing an involvement of $\mathrm{NF}-\kappa \mathrm{B}$ (a negative regulator of the expression of NEF2L2) (38), or rather an upregulation of KEAP1 during oxidative stress, thus leading to the inhibition of NEF2L2 $(40,41)$. Consistent with literature data on PC12 cells $(35,36)$, we observed in our experimental paradigm, that $\mathrm{H}_{2} \mathrm{O}_{2}$ markedly downregulated NFE2L2 expression, which was antagonized by pre-treatment with DHA.

In conclusion, in this study, we demonstrate that DHA is able to protect $\mathrm{PC} 12$ cells from $\mathrm{H}_{2} \mathrm{O}_{2}$-induced oxidative damage through a mechanism involving the activation of the NFE2L2/HO-1 signaling pathway. These findings suggest that a strong link could exist between an adequate supply in the diet of this essential PUFA and the maintenance of the antioxidant potential of the neuronal cells. Thus, in light of these findings, it can be hypothesized that DHA may prove to be a potential therapeutic agent for the prevention of diseases characterized by inflammation and oxidative stress at the central nervous system level.

\section{Acknowledgements}

Not applicable.

\section{Funding}

The present study was financed by the Italian National Research Council (CNR) funding to MEC and by internal funding (Fondi di Ateneo D1:2013-2018) to GT.

\section{Availability of data and materials}

All data generated or analyzed during this study are included in this published article.

\section{Authors' contributions}

MEC, GL and GT conceived and designed the study, performed the experiments, contributed to data analysis and wrote the manuscript. GL reviewed and supported MEC and GT in revisions of the manuscript. BS and AB performed the experiments, conceptualized the study design, and contributed to data analysis and experimental materials. All authors have read and approved the final manuscript.

\section{Ethics approval and consent to participate}

Not applicable.

\section{Patient consent for publication}

Not applicable. 


\section{Competing interests}

The authors declare that they have no competing interests.

\section{References}

1. Yan MH, Wang X and Zhu X: Mitochondrial defects and oxidative stress in Alzheimer disease and Parkinson disease. Free Radic Biol Med 62: 90-101, 2013.

2. Cheng YC, Sheen JM, Hu WL and Hun YC: Polyphenols and oxidative stress in atherosclerosis-related ischemic heart disease and stroke. Oxid Med Cell Longev 2017: 8526438, 2017.

3. Li J, O W, Li W, Jiang ZG and Ghanbari HA: Oxidative stress and neurodegenerative disorders. Int J Mol Sci 14: 24438-24475, 2013.

4. Shi H, Hudson LG and Liu KJ: Oxidative stress and apoptosis in metal ion-induced carcinogenesis. Free Radic Biol Med 37: 582-593, 2004

5. Wysoczański T, Sokoła-Wysoczańska E, Pękala J, Lochyński S, Czyż K, Bodkowski R, Herbinger G, Patkowska-Sokoła B and Librowski T: Omega-3 fatty acids and their role in central nervous system-a review. Curr Med Chem 23: 816-831, 2016.

6. Miller E, Kaur G, Larsen A, Loh SP, Linderborg K, Weisinger HS, Turchini GM, Cameron-Smith D and Sinclair AJ: A short-term n-3 DPA supplementation study in humans. Eur J Nutr 52 895-904, 2013.

7. Siegel $G$ and Ermilov E: Omega-3 fatty acids: Benefits for cardio-cerebro-vascular diseases. Atherosclerosis 225: 291-295, 2012.

8. Cardoso C, Afonso C and Bandarra NM: Dietary DHA and health: Cognitive function ageing. Nutr Res Rev 29: 281-294, 2016.

9. Wang W, Yang H, Johnson D, Gensler C, Decker E and Zhang G: Chemistry and biology of $\omega-3$ PUFA peroxidation-derived compounds. Prostaglandins Other Lipid Mediat 132: 84-91, 2017.

10. Smith RE, Tran K, Smith CC, McDonald M, Shejwalkar P and Hara K: The Role of the Nrf2/ARE antioxidant system in preventing cardiovascular diseases. Diseases 4: E34, 2016.

11. Vomund S, Schäfer A, Parnham MJ, Brüne B and von Knethen A: $\mathrm{Nrf2}$, the master regulator of anti-oxidative responses. Int J Mol Sci 18: E2772, 2017.

12. Dinkova-Kostova AT, Kostov RV and Kazantsev AG: The role of Nrf2 signaling in counteracting neurodegenerative diseases. FEBS J 285: 3576-3590, 2018

13. Cong P, Liu Y, Liu N, Zhang Y, Tong C, Shi L, Liu X, Shi X, Liu Y, Tong $\mathrm{Z}$ and Hou M: Cold exposure induced oxidative stress and apoptosis in the myocardium by inhibiting the Nrf2-Keap1 signaling pathway. BMC Cardiovasc Disord 18: 36, 2018.

14. Clementi ME, Pani G, Sampaolese B and Tringali G: Punicalagin reduces $\mathrm{H} 2 \mathrm{O} 2$-induced cytotoxicity and apoptosis in $\mathrm{PC} 12$ cells by modulating the levels of reactive oxygen species. Nutr Neurosci 21: 447-454, 2018.

15. Lazzarino G, Viola AR, Mulieri L, Rotilio G and Mavelli I: Prevention by fructose-1,6-bisphosphate of cardiac oxidative damage induced in mice by subchronic doxorubicin treatment. Cancer Res 47: 6511-6516, 1987.

16. McCord JM and Fridovich I: Superoxide dismutase. An enzymic function for erythrocuprein (hemocuprein). J Biol Chem 244: 6049-6055, 1969.

17. Noble JE: Quantification of protein concentration using UV absorbance and coomassie dyes. Methods Enzymol 536: 17-26, 2014.

18. Lazzarino G, Amorini AM, Fazzina G, Vagnozzi R, Signoretti S, Donzelli S, Di Stasio E, Giardina B and Tavazzi B: Single-sample preparation for simultaneous cellular redox and energy state determination. Anal Biochem 322: 51-59, 2003.

19. Amorini AM, Giorlandino C, Longo S, D'Urso S, Mesoraca A, Santoro ML, Picardi M, Gullotta S, Cignini P, Lazzarino D, et al: Metabolic profile of amniotic fluid as a biochemical tool to screen for inborn errors of metabolism and fetal anomalies. Mol Cell Biochem 359: 205-216, 2012.
20. Innamorato NG, Rojo AI, García-Yagüe AJ, Yamamoto M, de Ceballos ML and Cuadrado A: The transcription factor Nrf2 is a therapeutic target against brain inflammation. J Immunol 181: 680-689, 2008

21. Simopoulos AP: Omega-3 fatty acids in health and disease and in growth and development. Am J Clin Nutr 54: 438-463, 1991.

22. Uauy R and Dangour AD: Nutrition in brain development and aging: Role of essential fatty acids. Nutr Rev 64: S24-S33, 2006

23. Moore SA: Polyunsaturated fatty acid synthesis and release by brain-derived cells in vitro. J Mol Neurosci 16: 195-200, 2001.

24. Heras-Sandoval D, Pedraza-Chaverri J and Pérez-Rojas JM: Role of docosahexaenoic acid in the modulation of glial cells in Alzheimer's disease. J Neuroinflammation 13: 61, 2016.

25. Molz P and Schröder N: Potential therapeutic effects of lipoic acid on memory deficits related to aging and neurodegeneration. Front Pharmacol 8: 849, 2017.

26. Yadav RK, Singh M, Roy S, Ansari MN, Saeedan AS and Kaithwas G: Modulation of oxidative stress response by flaxseed oil: Role of lipid peroxidation and underlying mechanisms. Prostaglandins Other Lipid Mediat 135: 21-26, 2018.

27. Sakai C, Ishida $M$, Ohba $H$, Yamashita $H$, Uchida $H$, Yoshizumi M and Ishida T: Fish oil omega-3 polyunsaturated fatty acids attenuate oxidative stress-induced DNA damage in vascular endothelial cells. PLoS One 12: e0187934, 2017.

28. Matschke V, Theiss C and Matschke J: Oxidative stress: The lowest common denominator of multiple diseases. Neural Regen Res 14: 238-241, 2019.

29. Jiang S, Deng C, Lv J, Fan C, Hu W, Di S, Yan X, Ma Z, Liang Z and Yang Y: Nrf2 weaves an elaborate network of neuroprotection against stroke. Mol Neurobiol 54: 1440-1455, 2017.

30. Vomhof-Dekrey EE and Picklo MJ Sr: The Nrf2-antioxidant response element pathway: A target for regulating energy metabolism. J Nutr Biochem 23: 1201-1206, 2012.

31. Frankel D, Mehindate K and Schipper HM: Role of heme oxygenase-1 in the regulation of manganese superoxide dismutase gene expression in oxidatively-challenged astroglia. J Cell Physiol 185: 80-86, 2000.

32. Mo L, Yang C, Gu M, Zheng D, Lin L, Wang X, Lan A, Hu F and Feng J: PI3K/Akt signaling pathway-induced heme oxygenase-1 upregulation mediates the adaptive cytoprotection of hydrogen peroxide preconditioning against oxidative injury in PC12 cells. Int J Mol Med 30: 314-320, 2012.

33. Giudice A, Arra C and Turco MC: Review of molecular mechanisms involved in the activation of the Nrf2-ARE signaling pathway by chemopreventive agents. Methods Mol Biol 647: $37-74,2010$

34. Bellezza I, Giambanco I, Minelli A and Donato R: Nrf2-Keap1 signaling in oxidative and reductive stress. Biochim Biophys Acta Mol Cell Res 1865: 721-733, 2018.

35. Xu J, Gan S, Li J, Wand DB, Chen Y, Hu X and Yang GZ: Garcinia xanthochymus extract protects $\mathrm{PC} 12$ cells from $\mathrm{H} 2 \mathrm{O} 2$-induced apoptosis through modulation of PI3K/AKT and NRF2/HO-1 pathways. Chin J Nat Med 15: 825-833, 2017.

36. Li M, Xu T, Zhou F, Wang M, Song H, Xiao X and Lu B: Neuroprotective effects of four phenylethanoid glycosides on $\mathrm{H} 2 \mathrm{O} 2$-induced apoptosis on PC12 Cells via the Nrf2/ARE pathway. Int J Mol Sci 19: E1135, 2018.

37. Fourquet S, Guerois R, Biard D and Toledano MB: Activation of NRF2 by nitrosative agents and $\mathrm{H} 2 \mathrm{O} 2$ involves KEAP1 disulfide formation. J Biol Chem 285: 8463-8471, 2010.

38. Cheng J, Wang H, Zhang Z and Liang K: Stilbene glycoside protects osteoblasts against oxidative damage via Nrf2/HO-1 and NF-кB signaling pathways. Arch Med Sci 15: 196-203, 2019.

39. Maralani MN, Movahedian A and Javanmard ShH: Antioxidant and cytoprotective effects of L-Serine on human endothelial cells. Res Pharm Sci 7: 209-215, 2012

40. Kim HJ and Vaziri ND: Contribution of impaired NRF2-KEAP1 pathway to oxidative stress and inflammation in chronic renal failure. Am J Physiol Renal Physiol 298: F662-F671, 2010.

41. Liu X, Liu H, Zhai Y, Li Y, Zhu X and Zhang W: Laminarin protects against hydrogen peroxide-induced oxidative damage in MRC-5 cells possibly via regulating NRF2. Peer J 5: e3642, 2017. 